\title{
The underrated nervous system involvement by COVID-19
}

\author{
Hector R. Martinez ${ }^{1,2 *}$, Jose A. Figueroa-Sanchez ${ }^{1,2}$, Fernando Castilleja-Leal ${ }^{1,3}$, \\ Michel F. Martínez-Reséndez ${ }^{1,3}$, and Ana S. Ferrigno ${ }^{1}$ \\ ${ }^{1}$ Tecnologico de Monterrey, Escuela de Medicina y Ciencias de la Salud, Monterrey, Mexico; ${ }^{2}$ Instituto de Neurología y Neurocirugía, Nuevo León, \\ Mexico; ${ }^{3}$ Instituto de Medicina Interna, Hospital Zambrano Hellion, Tecnológico de Monterrey, San Pedro Garza García. Nuevo León, Mexico
}

\begin{abstract}
The severe acute respiratory syndrome coronavirus 2 (SARS-CoV-2) is a highly pathogenic virus that causes severe pneumonia and acute respiratory distress syndrome. On March 11,2020, this novel coronavirus was declared a pandemic by the World Health Organization. To date, millions of patients have been infected. Recent reports indicate that a substantial proportion of cases present with neurological symptoms. However, it remains to be elucidated whether these manifestations are secondary to direct nervous system invasion, indirect damage mediated by a systemic inflammatory response, or a combination of both. In this review, we explore the potential routes for central nervous system involvement, the possible pathogenic mechanisms in the nervous system and the conceivable neurological long-term sequela of infection by SARSCoV-2 infection. Future efforts should concentrate on clarifying the pathophysiology of the neurological component of COVID-19.
\end{abstract}

Key words: COVID-19. SARS-CoV-2. Coronavirus. Neurological manifestations. Nervous system.

\section{Compromiso del sistema nervioso por COVID-19}

\section{Resumen}

EI SARS-CoV-2 es un virus altamente patogénico que causa neumonía grave y síndrome de dificultad respiratoria aguda. El 11 de marzo de 2020, este nuevo coronavirus fue declarado como pandemia por la Organización Mundial de la Salud. Hasta la fecha, millones de pacientes se han infectado. Informes recientes indican que una proporción sustancial de casos presenta síntomas neurológicos. Sin embargo, aún no se ha dilucidado si estas manifestaciones son secundarias a una invasión directa del virus al sistema nervioso, efecto del daño indirecto mediado por una respuesta inflamatoria sistémica o el resultado de una combinación de ambas situaciones. En esta revisión se describen las posibles vías para la invasión del sistema nervioso central por SARS-CoV-2 y sus mecanismos patogénicos en el sistema nervioso y las secuelas neurológicas de infección a largo plazo. Se requieren investigaciones adicionales para precisar la fisiopatología del componente neurológico del COVID-19.

Palabras clave: COVID-19. SARS-CoV-2. Coronavirus. Sistema nervioso.

\section{Correspondence:}

*Hector R. Martínez

E-mail: hector.ramon@tec.mx
Date of reception: 10-05-2020

Date of acceptance: 02-06-2020

DOI: $10.24875 / R M N .20000037$
Available online: $05-08-2020$ Rev Mex Neuroci. 2020;21(4):158-162 www.revmexneurociencia.com 1665-5044/ @ 2020 Academia Mexicana de Neurología A.C. Published by Permanyer. This is an open access article under the CC BY-NC-ND license (http://creativecommons.org/licenses/by-nc-nd/4.0/). 


\section{Introduction}

The Coronaviridae family is comprised by enveloped positive-sense single-stranded RNA viruses, some of which are capable of causing human infection. These include several alpha-coronaviruses (human coronavirus [HCoV]-NL63 and HCoV-229E) and beta-coronaviruses (HCoV-HKU1, HCoV-OC43, Middle East respiratory syndrome-CoV [MERS-CoV], and severe acute respiratory syndrome [SARS-CoV]) 1 . In December 2019, a highly pathogenic coronavirus (CoV) emerged in Wuhan, China and rapidly spread around the world ${ }^{2,3}$. Initially, this pathogen was named as 2019 novel CoV (2019-nCoV) by the World Health Organization. After a similar viral structure and infection pathway was discovered between this novel virus and SARSCoV, the official name was changed to SARS-CoV-24,5. The diseases caused by this $\mathrm{nCoV}$ are mostly related to the respiratory system and are named CoV disease 2019 (COVID-19) ${ }^{5}$.

Even though the most widely recognized organ affected by CoVs is the respiratory system, it is important to note that CoV are not exclusively confined to the respiratory tract $^{6}$. In fact, the neuroinvasive ability of this pathogen has been documented for almost all beta-coronaviruses in animal (mouse hepatitis virus [MHV] and porcine hemagglutinating encephalitis virus) and human (HCoV-229E, HCoV-OC43, SARS-CoV, and MERS-CoV) hosts ${ }^{1,7,8}$. Because of the high similarity between SARS-CoV and the novel SARS-CoV-2, it is likely that this new pathogen has analogous neuroinvasive properties. Moreover, it has been described that $36-84 \%$ of hospitalized patients with COVID-19 manifest neurological symptoms, underscoring the potential nervous system involvement by this disease ${ }^{9,10}$. Thus, it is important to examine the possible routes of infection by this pathogen and the neurological manifestations that patients affected by this disease might express.

\section{Routes for nervous system involvement by SARS-CoV-2}

The main mode of human-to-human transmission of the SARS-CoV-2 infection is presumed to be by respiratory droplets, which allows the virus to come into contact with mucosal epithelium (e.g., nasal mucosa) and invade susceptible cells ${ }^{11}$. Specifically, it has been demonstrated that this virus exhibits a high affinity to the angiotensin-converting enzyme 2, a cellular receptor that is ubiquitously expressed by respiratory epithelium, lung parenchyma,

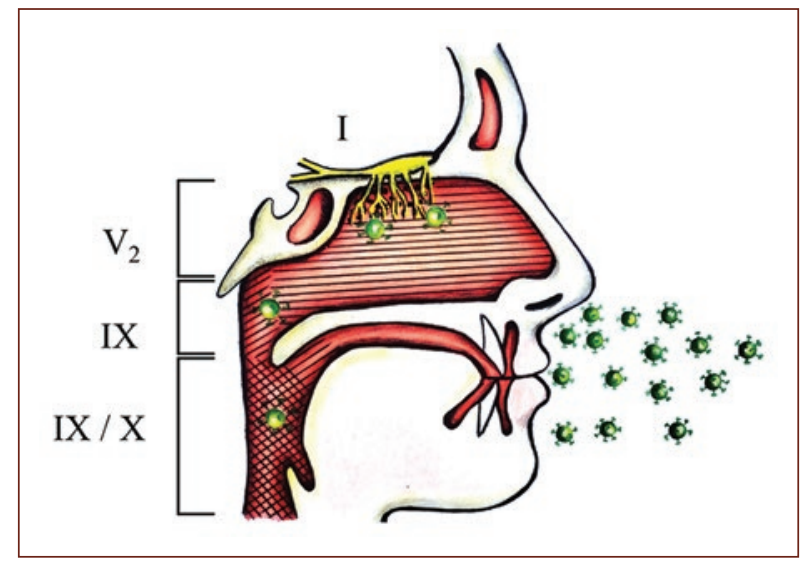

Figure 1. Potential routes of CNS invasion by SARS-CoV-2 through retrograde axonal transport from the olfactory (I), trigeminal (V), glossopharyngeal (IX), and vagus (X) cranial nerves.

vascular endothelium renal tissue, small intestine cells, neurons and glial cells, among others ${ }^{5,6}$.

Experimental models using transgenic mice have revealed that intranasal CoV inoculation could result in central nervous system (CNS) infection through retrograde axonal transport from olfactory nerves ${ }^{12,13}$. Hence, SARS-CoV-2 present in nasopharyngeal structures could access the brain similarly by invading local cranial nerves (i.e., olfactory, trigeminal, glossopharyngeal, and vagus nerves) (Fig. 1). Furthermore, it has been postulated that other potential pathways of invasion in patients with this disease is through the enteric nervous system or the hematogenous route ${ }^{8,14}$. Specifically, viremia could result in subsequent invasion of the CNS by infected leukocytes or through the endothelium of the blood-brain barrier ${ }^{1}$. In addition, circumventricular organs as well as dorsal root and autonomic ganglia which lack a blood-nerve barrier could act as potential hematogenous routes for pathogen entry into the CNS ${ }^{15,16}$. Thus, considering that multiple pathways for neurological invasion of the CNS exist, neurological manifestations of COVID-19 could be more frequent than initially presumed.

\section{Potential mechanisms of neurological manifestations of SARS-CoV-2}

A variety of neurological manifestations have been attributed to SARS-CoV-2 infection, ranging from headache to acute cerebrovascular events ${ }^{17}$. The mechanism of the neurological disease exhibited by COVID-19 
patients might be a consequence of direct viral invasion of the nervous system, indirect CNS injury by abolition of systemic homeostasis, or a combination of both ${ }^{4-6}$. However, how to differentiate if a manifestation of the disease is a consequence of direct damage to the nervous system or evidence of systemic derangements is currently unclear.

Notably, the CoVs have been shown to mediate nervous system damage through virus-mediated injury to neurons and glial cells, as well as through damage mediated by the activation of the immune system ${ }^{8}$. On the other hand, indirect neurological manifestations can occur when there is a widespread dysregulation of homeostasis secondary to multiple organ involvement. It is now evident that SARS-CoV-2 can precipitate multiple organ failure, shock, heart failure, arrhythmias, and renal injury in addition to pneumonia and acute respiratory distress syndrome ${ }^{18}$. These presentations might be secondary to hypoxia, hypercoagulability, and release of excessive pro-inflammatory cytokines, which have the potential to indirectly cause neurological symptoms without CNS invasion by the virus ${ }^{19,20}$. Furthermore, the release of cytokines caused by viral infection could result in the permeabilization of the blood-brain barrier, allowing the invasion of the CNS by $T$ lymphocytes and resulting in neuroinflammation $^{21,22}$. Such disruption of the blood-brain barrier could facilitate the entry of SARS-CoV-2 through the hematogenous route, thus resulting in concurrent direct and indirect damage of the CNS mediated by this pathogen 22 .

To elucidate the nervous pathophysiology of SARS-CoV-2 infection, it has been proposed that direct invasion of the CNS can be supported by the presence of viral RNA in cerebrospinal fluid (CSF). Nonetheless, failure to detect virus in the CSF does not exclude invasion of the CNS as illustrated in a case report by Paniz-Mondolfi et al. ${ }^{23}$. Consequently, further research is needed to determine which markers can be useful to distinguish between the direct involvement of the nervous system by SARS-CoV-2 and nervous injury secondary to systemic inflammation.

\section{Reports of neurological manifestations in COVID-19 patients}

Two large retrospective case series have examined the prevalence of neurological manifestations in patients hospitalized with COVID-19. Mao et al ${ }^{9}$. analyzed data from three centers located in Wuhan, China, including a total of 214 hospitalized COVID-19 patients. They found that $36.4 \%$ of their cohort exhibited neurological symptoms: $36(16.8 \%)$ manifested dizziness, 28 (13.1\%) headache, 23 (10.7\%) skeletal muscle injury, $16(7.5 \%)$ altered mental status, 12 (5.6\%) hypogeusia, 11 (5.1\%) hyposmia, 6 (2.8\%) acute cerebrovascular disease, 5 (2.3\%) neuralgia, 3 (1.4\%) vision impairment, $1(0.5 \%)$ ataxia, and $1(0.5 \%)$ seizures. On the other hand, Helms et $\mathrm{al}^{10}$. reported the findings of 58 COVID-19 patients admitted to two intensive care units located in Strasbourg, France. They discovered neurological signs in $49(84 \%)$ of their cohort: $40 / 58(69 \%)$ presented agitation, 39/58 $(67 \%)$ corticospinal tract signs, $26 / 40(65 \%)$ confusion, $14 / 39(36 \%)$ dysexecutive syndrome, and $8 / 49$ (16\%) fever $>38.5^{\circ} \mathrm{C}$. Of the 13 patients that had a brain MRI because of unexplained encephalopathic features, $11 / 11(100 \%)$ presented perfusion abnormalities, 8 $(62 \%)$ leptomeningeal enhancement, and $3(23 \%)$ cerebral ischemic stroke. CSF samples were analyzed for seven cases, all of which had a negative reverse transcription-polymerase chain reaction for SARSCoV-2, which suggests that the neurologic clinical findings could have been secondary to indirect CNS injury or toxic encephalopathy.

In addition to the aforementioned studies, the study performed by Li et $\mathrm{al}^{24}$. merits mention as they assessed the prevalence of cerebrovascular disease in hospitalized patients with COVID-19. In 211 consecutive patients were admitted to a center in Wuhan China, $11(5 \%)$ developed acute cerebrovascular ischemic stroke, $1(0.5 \%)$ exhibited cerebral venous sinus thrombosis, and 1 $(0.5 \%)$ presented with intracerebral hemorrhage.

Several authors have published case-series and case reports of neurological manifestations of COVID-19. These reports comprise patients aged from 24 to 79 years presenting with a variety of symptoms such as headache, altered mental status, seizures, neck rigidity, muscle weakness, incontinence, and corticospinal tract signs. The neurological diagnosis established in such cases include Guillain-Barre syndrome $^{25,26}$, encephalopathy ${ }^{27,28}$, meningoencephalitis ${ }^{2}$, acute myelitis ${ }^{29}$, and intracerebral hemorrhage ${ }^{30}$.

Noteworthy, another neurological manifestation of COVID-19 that has been proposed is neurogenic respiratory failure, which together with diffuse alveolar damage, results in difficult to treat hypoxia characteristic of severe COVID-19 cases. In particular, several authors have advocated for brain stem dysfunction caused by direct viral invasion as a possible cause for respiratory and cardiovascular derangements observed in SARSCoV-2 infection ${ }^{4,15,31}$. 
In summary, the amount of evidence available indicates that COVID-19 is irrefutably associated with neurologic manifestations. However, to what extent these manifestations are a consequence of direct viral mediated damage has not been elucidated.

\section{Potential long-term repercussions of COVID-19 infection}

It has been previously described that CoVs have the potential to produce chronic infections in the $\mathrm{CNS}^{7,8}$. This can have significant clinical implications as the persistence of the viral infection could be associated with long-term neurological sequela and predispose to the development or progression of neurodegenerative and demyelinating disorders.

To date, there is no definitive evidence that links human infection by CoV to the development of chronic neurological diseases. Nonetheless, the presence of HCoV-229E and HCoV-OC43 RNA has been demonstrated in the CNS of patients with Parkinson's disease, Alzheimer's disease, multiple sclerosis (MS), and acute disseminated encephalomyelitis ${ }^{8}$. Particularly, the proportion of patients with detectable HCoV-OC43 RNA in brain parenchyma of patients with MS has been shown to be statistically significantly increased compared to healthy controls ${ }^{32}$. While it remains to be elucidated if persistent $\mathrm{CoV}$ infection plays a role in the pathogenesis of MS in humans, murine models have demonstrated that chronic MHV infection can induce immune-mediated demyelination 7 . Furthermore, persistence of $\mathrm{HCOV}-\mathrm{OC} 43 \mathrm{RNA}$ in CNS of mice was associated with neuronal degeneration with secondary motor deficits appearing several months after acute infection by intracerebral inoculation, supporting the pathogenic role of chronic CoV infection ${ }^{33}$.

Of note, even in the absence of chronic presence of SARS-CoV-2 in the CNS, COVID-19 infection may have long-term neurologic sequela as a consequence of microglial priming and astrogliosis. These cells might become chronically active and release pro-inflammatory cytokines even after the initial stimulus for the inflammatory response has been eliminated, possibly leading to chronic neuroinflammation even in the absence of active infection ${ }^{22,31}$.

Consequently, as no information is currently available about the ability (of lack thereof) of SARS-CoV-2 infection to persist in CNS and mediate chronic neuronal damage, its potential to cause long-term sequela should not be dismissed.

\section{Conclusion}

Infection by SARS-CoV-2 might be associated with significant nervous involvement. However, the specific pathways for nervous system invasion and the mechanisms for neurological disease are currently unknown. As the magnitude of the acute neurological manifestations and the potential long-term repercussions of this disease are unclear, future efforts should concentrate on elucidating the pathophysiology of the neurological component of COVID-19.

\section{Conflicts of interest}

The authors declare that the research was conducted in the absence of any commercial or financial relationships that could be construed as a potential conflict of interest.

\section{Sources of funding}

The authors declare that the research was conducted in the absence of any funding.

\section{Acknowledgments}

The authors thank Celene Rocha Reza for her permission to use the figure included in this article.

\section{Ethical disclosures}

Protection of human and animal subjects. The authors declare that no experiments were performed on humans or animals for this study.

Confidentiality of data. The authors declare that no patient data appear in this article.

Right to privacy and informed consent. The authors declare that no patient data appear in this article.

\section{References}

1. Desforges M, Le Coupanec A, Dubeau P, Bourgouin A, Lajoie L, Dubé M, et al. Human coronaviruses and other respiratory viruses: underestimated opportunistic pathogens of the central nervous system? Viruses. 2019;12:14.

2. Moriguchi T, Harii N, Goto J, Harada D, Sugawara H, Takamino J, et al. A first case of meningitis/encephalitis associated with SARS-coronavirus-2. Int J Infect Dis. 2020;94:55-8

3. Wang $Y$, Wang $Y$, Chen $Y$, Qin Q. Unique epidemiological and clinical features of the emerging 2019 novel coronavirus pneumonia (COVID-19) implicate special control measures. J Med Virol. 2020;92:568-76.

4. Li YC, Bai WZ, Hashikawa T. The neuroinvasive potential of SARS-CoV2 may be at least partially responsible for the respiratory failure of $\mathrm{CO}$ VID-19 patients. J Med Virol. 2020;(6);552-5.

5. Baig AM, Khaleeg A, Ali U, Syeda H. Evidence of the COVID-19 virus targeting the CNS: tissue distribution, host-virus interaction, and proposed neurotropic mechanisms. ACS Chem Neurosci. 2020; 11:995-8. 
6. Wu Y, Xu X, Chen Z, Duan J, Hashimoto K, Yang L, et al. Nervous system involvement after infection with COVID-19 and other coronaviruses. Brain Behav Immun. 2020 [Epub ahead of print].

7. Bergmann CC, Lane TE, Stohlman SA. Coronavirus infection of the central nervous system: host-virus stand-off. Nat Rev Microbiol. 2006;4:121-32.

8. Desforges M, Le Coupanec A, Stodola JK, Meessen-Pinard M, Talbot PJ. Human coronaviruses: viral and cellular factors involved in neuroinvasiveness and neuropathogenesis. Virus Res. 2014;194:145-58.

9. Mao L, Jin H, Wang M, Hu Y, Chen S, He Q, et al. Neurologic manifestations of hospitalized patients with coronavirus disease 2019 in Wuhan, China. JAMA Neurol. 2020;2020:e201127.

10. Helms J, Kremer S, Merdji H, Clere-Jehl R, Schenck M, Kummerlen C et al. Neurologic features in severe SARS-CoV-2 infection. N Engl J Med. 2020;382:2268-70.

11. Zhou M, Zhang X, Qu J. Coronavirus disease 2019 (COVID-19): a clinical update. Front Med. 2020;14:126-35

12. Netland J, Meyerholz DK, Moore S, Cassell M, Perlman S. Severe acute respiratory syndrome coronavirus infection causes neuronal death in the absence of encephalitis in mice transgenic for human ACE2. J Virol. 2008;82:7264-75.

13. Dubé M, Le Coupanec A, Wong AH, Rini JM, Desforges M, Talbot PJ. Axonal transport enables neuron-to-neuron propagation of human coronavirus OC43. Am Soc Microbiol. 2018;92:e00404-18.

14. Pereira A. Long-term neurological threats of COVID-19: a call to update the thinking about the outcomes of the coronavirus pandemic. Front Neurol. 2020;11:308.

15. Román GC, Spencer PS, Reis J, Buguet A, El Alaoui Faris M, Katrak SM, et al. The neurology of COVID-19 revisited: a proposal from the environmental neurology specialty group of the world federation of neurology to implement international neurological registries. J Neurol Sci. 2020;414:116884.

16. Chigr F, Merzouki M, Najimi M. Comment on the neuroinvasive potential of SARS-CoV-2 may play a role in the respiratory failure of COVID-19 patients. J Med Virol. 2020;25960.

17. Asadi-Pooya AA, Simani L. Central nervous system manifestations of COVID-19: a systematic review. J Neurol Sci. 2020;413:116832.

18. Wang T, Du Z, Zhu F, Cao Z, An Y, Gao Y, et al. Comorbidities and multi-organ injuries in the treatment of COVID-19. Lancet. 2020;395:e52.

19. Connors JM, Levy JH. Thromboinflammation and the hypercoagulability of COVID-19. J Thromb Haemost. 2020;14849.
20. Mehta P, McAuley DF, Brown M, Sanchez E, Tattersall RS, Manson JJ, et al. COVID-19: consider cytokine storm syndromes and immunosuppression. Lancet. 2020;395:1033-4.

21. Varatharaj A, Galea I. The blood-brain barrier in systemic inflammation. Brain Behav Immun. 2017;60:1-12.

22. Ogier M, Andéol G, Sagui E, Dal Bo G. How to detect and track chronic neurologic sequelae of covid-19? Use of auditory brainstem responses and neuroimaging for long-term patient follow-up. Brain Behav Immun Health. 2020;5:100081

23. Paniz-Mondolfi A, Bryce C, Grimes Z, Gordon RE, Reidy J, Lednicky J, et al. Central nervous system involvement by severe acute respiratory syndrome coronavirus-2 (SARS-CoV-2). J Med Virol. 2020;25915.

24. Li Y, Wang M, Zhou Y, Chang J, Xian Y, Mao L, et al. Acute cerebrovascular disease following COVID-19: a single center, retrospective, observational study. SSRN Electron J. 2020 [Epub ahead of print]

25. Toscano G, Palmerini F, Ravaglia S, Ruiz L, Invernizzi P, Franciotta D, et al. Guillain-barré syndrome associated with SARS-CoV-2. N Engl J Med 2020 [Epub ahead of print].

26. Zhao H, Shen D, Zhou H, Liu J, Chen S. Correspondence guillain-barré syndrome associated with SARS-CoV-2 infection: causality or coincidence? Lancet Neurol. 2020;19:P383-4.

27. Filatov A, Sharma P, Hindi F, Filatov A. Neurological complications of coronavirus disease (COVID-19): encephalopathy. Cureus. 2020;12:e7930.

28. Poyiadji N, Shahin G, Noujaim D, Stone M, Patel S, Griffith B. COVID-19-associated acute hemorrhagic necrotizing encephalopathy: CT and MRI features. Radiology. 2020;201187.

29. Zhao K, Huang J, Dai D, Feng Y, Liu L, Nie S. Acute myelitis after SARSCoV-2 infection: a case report. MedRxiv. 2020 [Epub ahead of print].

30. Sharifi-Razavi A, Karimi N, Rouhani N. COVID 19 and intra cerebral hemorrhage: causative or coincidental. New Microbes New Infect. 2020;35:100669.

31. Steardo L, Steardo L, Zorec R, Verkhratsky A. Neuroinfection may contribute to pathophysiology and clinical manifestations of COVID-19. Acta Physiol. 2020;3:e13473.

32. Arbour N, Day R, Newcombe J, Talbot PJ. Neuroinvasion by human respiratory coronaviruses. J Virol. 2000;74:8913-21.

33. Jacomy H, Fragoso G, Almazan G, Mushynski WE, Talbot PJ. Human coronavirus OC43 infection induces chronic encephalitis leading to disabilities in BALB/C mice. Virology. 2006;349:335-46. 